\title{
Importance of ectopic thyroid tissue detected in the midline of the neck: single center experience
}

Ayten Oguz', Dilek Tuzun', Elif Ozdemir², Reyhan Ersoy³, Aylin Kilic Yazgan ${ }^{4}$, Bekir Cakir ${ }^{3}$

\begin{abstract}
Objective: Ectopic thyroid tissue (ETT) is a rare abnormality of the thyroid gland and the true prevalence and importance is not known. The aim of this study was to evaluate ultrasonography (US) guided fine needle aspiration biposy (FNAB) results, sonographic features, and frequency of ETT detected in the midline of the neck. Subjects and methods: Five thousand five hundred and twenty outpatients who were referred to our thyroid clinic between September 2010 and April 2012 and underwent thyroid US, were retrospectively analyzed. Patients with ETT, detected in the midline of the neck in US were included in the study. Thyroid functions, sonographic features, and US guided FNAB results were evaluated. Results: There were $81(81.8 \%)$ female and $18(18.2 \%)$ male patients with a mean age of $50.9 \pm 11.7$. The ETT in the midline was present in $1.79 \%(99 / 5,520)$ of the patients. In the majority of the patients, benign sonographic features (isoechoic, regular margin, type 1 vascularization) were detected. There were $92(92.9 \%)$ patients with a previous history of thyroidectomy and all were histopathologically benign. In $7(7.1 \%)$ patients, there was no history of thyroid operation. FNAB results of ETT were benign. Conclusion: This study evaluated the importance of ETT detected incidentally in the midline of the neck. Especially in patients with a history of thyroidectomy, the thyroid masses in the midline of the neck can be found as incidental with imaging methods. Our results suggests that the incidence of malignancy in this group is much lower than orthotopic thyroid nodules and they are often benign. Arch Endocrinol Metab. 2016;60(3):231-5
\end{abstract}

Keywords

Ectopic thyroid tissue; sonographic features; fine needle aspiration biopsy

\author{
1 Ankara Atatürk Education \\ and Research Hospital, \\ Department of Endocrinology \\ and Metabolism, Ankara, Turkey \\ ${ }^{2}$ Yıldırım Beyazıt University, Faculty \\ of Medicine, Department of \\ Nuclear Medicine, Ankara, Turkey \\ ${ }^{3}$ Yildirim Beyazit University, \\ Faculty of Medicine, Department \\ of Endocrinology and \\ Metabolism, Ankara, Turkey \\ ${ }^{4}$ Yıldırım Beyazıt University, \\ Ankara Atatürk Education and \\ Research Hospital, Department \\ of Pathology, Ankara, Turkey \\ Correspondence to: \\ Ayten Oguz \\ Kayseri Yolu 10. km \\ Avşar Kampüsü Kahramanmaraş \\ Sütçü İmam Üniversitesi \\ 46100 - Kahramanmaras, Turkıye \\ aytenoguz@windowslive.com \\ Received on May/7/2015 \\ Accepted on May/27/2015 \\ DOI: $10.1590 / 2359-3997000000073$
}

\section{INTRODUCTION}

$\mathrm{T}$ hyroid gland is located in front of the trachea between C5-Tl vertebrae. It's derived from the foramen cecum at the back of the tongue and descends down. Thyroglossal duct remains open for a short time and then degenerate (1). Ectopic thyroid tissue (ETT) is a rare entity resulting from developmental defects at early stages of thyroid gland embryogenesis, during its passage from the floor of the primitive foregut to its final pre-tracheal position. As a result of defects during organogenesis various morphological variations of thyroid gland such as pyramidal lobe, thyroglossal duct cyst, hypoplasia, hemiagenesis and agenesis occurs. As the morphological variations are usually diagnosed incidentally, the true incidence is therefore unknown. It is frequently found around the course of the thyroglossal duct (midline of neck) or laterally in the neck, as well as in distant places such as the mediastinum and the subdiaphragmatic organs (2). Developmental abnormali- ties of the thyroid gland may cause clinical functional disorders and goitrogenic enlargement as well as adenomatous and malign transformation may ocur $(3,4)$. Malign transformation has been reported in thyroglossal duct (5), pyramidal lobe (6) and as well as in other ETT (4). However, sonographic features ETT's and FNAB indication is not known exactly. Therefore, in this study we aimed to evaluate US guided FNAB results, prevalence and sonographic features of ETT detected in the midline of the neck.

\section{SUBJECTS AND METHODS}

\section{Study protocol}

This retropective study was carried out between September 2010 and April 2012. Thyroid ultrasonography (US) was performed to 5,520 outpatients, who were referred to our thyroid clinic because of thyroid dysfunction and/or palpabl thyroid nodules determi- 
ned in physical examination. Ninety nine patients, detected ETT (length longer than $10 \mathrm{~mm}$ ) in the midline of the neck were recruited for the study. ETT in the midline of the neck was defined as tissue found around the course of the thyroglossal duct, outside of ortotopic thyroid tissue located anterolaterally to the second to fourth tracheal cartilages. It was approved by the local ethical committee and written informed consent was obtained from all subjects.

Demographic datas, thyroid function parameters [thyroid stimulating hormone (TSH), free triiodothyronine (fT3) and free thyroxine (fT4)] were examined in patients with ETT in the midline of neck and thyroid US was carried out. Thyroid US was performed by an experienced specialist using the same US machine. Tc $99 \mathrm{~m}$ pertechnetate scintigraphy was performed to only 99 patients with ETT in the midline of neck detected in ultrasonography, as well as confirmation of the diagnosis and for differential diagnosis. FNAB was performed to ETT with length longer than $10 \mathrm{~mm}$. FNAB was carried out by an experienced specialist. Cytological evaluation was made by the same cytologist experienced in thyroid cytology. FNAB was repeated in tissue with nondiagnostic cytology results.

\section{Exclusion criteria}

Patients who have been operated for thyroid cancer or head and neck cancer, received RAI therapy, or radiotherapy and under 16 years of age were excluded.

\section{Laboratory examination}

Serum TSH, fT3, fT4 were measured by chemiluminescence methods using commercial kits (Chemiluminescent Microparticle Immunoassay, CIMA) with Abott Arhictec machine.

\section{Ultrasonography}

Ultrasonography Esaote color Doppler US (MAG Tecnology Co, Ltd. Model: 796FDII Yung-ho City, Taipei, Taiwan) and a superficial probe (Model No: LA523 $13-4,5.5-12.5 \mathrm{MHz}$ ) were used for standard US. The sonograms were evaluated retrospectively by two reviewers for the following features: location of the mass, volume, echogenicity of the internal contents, marginal regularity, type of calcification and vascularization pattern (stage 1: absence of blood flow; stage 2: peripheral vascularization; stage 3: intranodular vascularization; stage 4: marked intranodular vascularization). ETT was classi- fied into four categories according to the location of the upper end: tongue base, hyoid bone, thyrohyoid membrane, and thyroid cartilage. Internal echogenicity was classified as isoechoic (similar echogenic with adjacent tissues), hypoechoic (lower amplitude echoes than surrounding tissue), or hyperechoic (more echogenic than adjacent tissues). Marginal regularity also was classified as either irregulary or regulary. Calcification was classified into four categories: no calcification, microcalcification, macrocalcification, and rim calcification. Microcalcification was defined as hyperechoic spots less than $1 \mathrm{~mm}$ in diameter with or without posterior acoustic shadowing.

\section{US guided FNAB}

US guided FNAB was performed under US guidance using a General Electric Logiq pro200 (Model number: 2270968, GE Healthcare Korea, Seongnam-SI, Gyeon GGI-DO, Korea) and a 5.5-7.5-MHz probe.

\section{Thyroid scintigraphy}

The Tc-99m pertechnetate thyroid scintigraphies were performed to verify the localization of ectopic tissue in all patients.

\section{Cytological and histopathological examination}

Pathologic correlation was obtained by reviewing the medical records, including pathology reports, from all patients. Materials obtained by US guided FNAB were air-dried, stained with the May-Grünwald-Giemsa stain, and evaluated according to Bethesda system classification (7).

\section{Statistical analysis}

Statistical analyses were performed using SPSS for Windows (version 15.0.1; SPSS, Inc. Chicago, IL). Descriptive statistics were done.

\section{RESULTS}

The distrubition of frequency, age, sex, operation history, thyroid status in the patients with ETT in the midline of neck are summarized in table 1. ETT in the midline of neck was present in $1.79 \%(99 / 5520)$ of the patients. Ninety-two patients $(92.9 \%)$ had a previous history of thyroidectomy (56.5\% lobectomy, $44.5 \%$ subtotal thyroidectomy) while 7 (7.1\%) patients had no history of the thyroidectomy. Seventy six point eight percent of patients was euthyroid. Thirteen point 
one percent and $10.1 \%$ of patients were hypothyroid (taking L-thyroxin treatment and euthyroid with the treatment) and hyperthyroid (taking thionamide treatment and euthyroid with the treatment), respectively.

Ultrasonographic features and FNAB results of patients with ETT in the midline of neck are summarized in table 2. There were benign ultrasonographic features in the majority of the patients.

Table 1. The distribution of frequency, age, sex, operation history, thyroid status in the patients with ectopic thyroid tissue in the midline of the neck

\begin{tabular}{lc}
\hline & $\begin{array}{c}\text { Patients with ETT } \\
\text { [n(\%)] }\end{array}$ \\
\hline $\begin{array}{l}\text { Frequency in each sex } \\
\text { Female }\end{array}$ & $81(81.8)$ \\
Male & $18(18.2)$ \\
Age (mean) & $50.9 \pm 11.7$ \\
Thyroid function & \\
$\quad$ Euthyroid & $76(76.8)$ \\
Hypothyroid & $13(13.1)$ \\
Hyperthyroid & $10(10.1)$ \\
Operation history & \\
Yes & $92(92.9)$ \\
No & $7(7.1)$ \\
\hline
\end{tabular}

ETT: ectopic thyroid tissue.

Table 2. Sonographic features and FNAB results in the patients with ectopic thyroid tissue in the midline of the neck

\begin{tabular}{lc}
\hline & $\begin{array}{c}\text { Patients with ETT } \\
\text { [n (\%)] }\end{array}$ \\
\hline Echogenicity & \\
Isoechoic & $83(83.9)$ \\
Hyperechoic & $11(11.1)$ \\
Hypoechoic & $5(5)$ \\
Cystic degeneration & \\
Yes & $12(12.1)$ \\
No & $87(87.9)$ \\
Calcification & \\
no & $91(91.9)$ \\
Micro & $3(3)$ \\
Macro & $5(5)$ \\
Rim & $0(0)$ \\
Margin regularity & \\
Regular & $96(97)$ \\
Irregular & $3(3)$ \\
Vascularization & \\
Type 1 & $62(62.6)$ \\
Type 2 & $35(35.4)$ \\
Type 3 & $2(2)$ \\
Type 4 & $0(0)$ \\
Localization & \\
Tongue base & \\
Hyoid bone & \\
Thyroid cartilage & $0(0)$ \\
Thyrohyoid membrane & $70(70.7)$ \\
FNAB (benign thyroid follicular cells) & $14(14.2)$ \\
\hline & $15(15.1)$ \\
\hline ing & $99(100)$ \\
\hline
\end{tabular}

FNAB: fine needle aspiration biopsy.
FNAB results of all ETT in the midline of neck were benign thyroid follicular cells.

Scintigraphic and sonographic appearance of ETT in the midline of neck is seen in figures 1 and 2 .
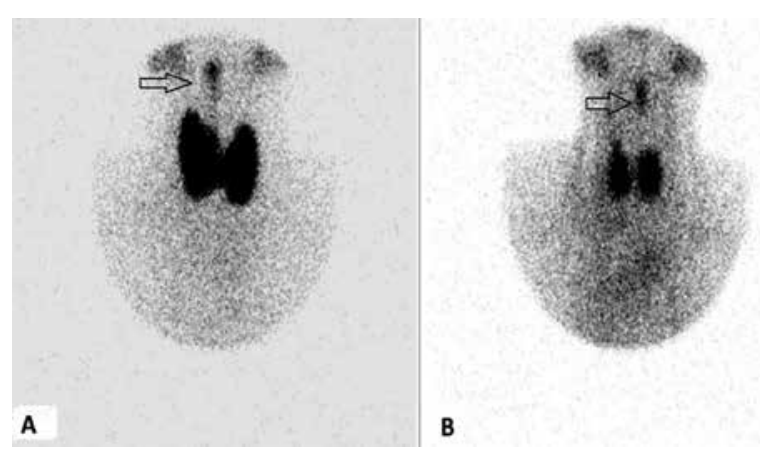

Figure 1. Scintigraphic appearance of ectopic thyroid tissue in a euthyroid patient (A) and a hypothyroid patient (B).

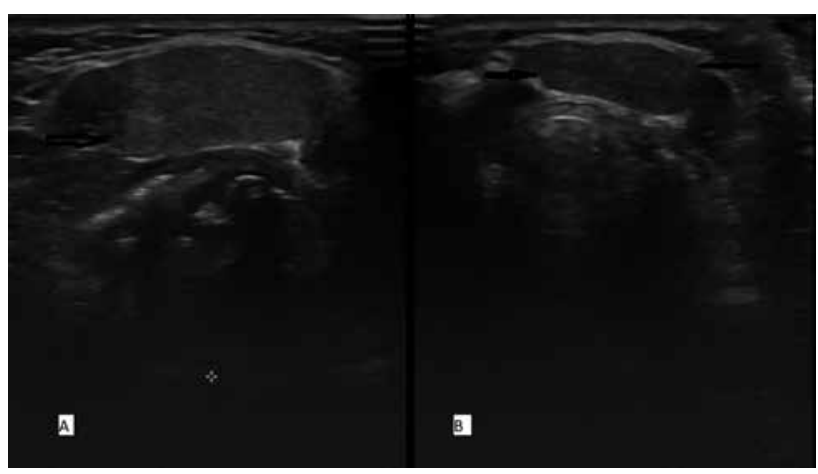

Figure 2. Sonographic appearance of ectopic thyroid tissue in a euthyroid patient (A) and a hypothyroid patient (B).

\section{DISCUSSION}

Thyroid gland is an endocrine organ, located in front of the trachea, however, it has various anatomical and developmental anomalies which are ectopic thyroids, accessory thyroids, and retrotracheal extensions (8). The most common localization of ectopic thyroid is tongue, midline and lateral of neck region (9-11). Ectopic thyroid tissue is a rare abnormality of the thyroid gland and the true prevalence and importance is not known. Therefore, in this study, we aim to evaluate US guided FNAB results and sonographic features, frequency of ETT detected in the midline of the neck.

Ectopic thyroid tissue in the midline of the neck, often occurs as a result of various defects during organogenesis or a result of post-surgical seeding. It was reported that this tissue becomes hypertrophic under the influence of increased thyrotrophin in thyroidecto- 
mized patients (12). Similarly, most of our patients had previous thyroidectomy history.

Ectopic thyroid tissue is rarely seen and often determined incidentally in asymptomatic patients (13). The prevalance of ETT is about 1 per $100,000-300,000$ people, and 1 in 4,000 to 8,000 patients with the thyroid diseases and male to female ratio is $1 / 4(14,15)$. However, in autopsy studies, the prevalence was found $7-10 \%$ $(16,17)$. Ectopic thyroid tissue is most common in older than 40 years, especially in populations of Asian origin $(18,19)$. In our study, prevalence of ETT was found $1.79 \%$ in the patients with the thyroid diseases and male to female ratio was $1 / 4.5$. Neck US is not routinely performed worldwide, so ETT may be overlooked, this should be the reason of high prevelance in our study.

Anterior midline thyroid ectopia is most commonly derived from thyroglossal duct remnants, which are thyroglossal duct cyst and lingual thyroid, as well as pyramidal lobe (20). Differential diagnosis of ETT in the midline of the neck is not always very easy. Probably, most of our cases may be thyroglossal duct remnant or pyramidal lobe. In our study, normal anatomy was deteriorated because of operation history of the most patients, so we could not assessed the masses, whether they are thyroglossal remnant or pyramidal lobe.

In $30 \%-70 \%$ of reported cases, the ectopic tissues were functionally hypothyroid; only a few cases were hyperthyroid (21). In our series, $76.8 \%$ patients with ETT was euthyroid (not under L-thyroxin treatment), $13.1 \%$ hypothyroid, $10.1 \%$ was hyperthyroid.

As in the thyroid gland, goitrogenic enlargement, adenomatous and malignant transformation may ocur also in the ETT $(3,4)$. Primary thyroid carcinomas arising from ETT are uncommon and have been reported in cases of lingual thyroid, thyroglossal duct cyst and pyramidal lobe, lateral aberrant thyroid tissue, mediastinal, and struma ovarii. Most tumors are papillary carcinomas. However, follicular, mixed follicular, and papillary Hurthle cell and medullary carcinomas have also been described (21). Thyroglossal remnant carcinomas (TRC) have been reported about $0.7-1.5 \%$ (22). Our data ( malignancy rate $0 \%$ ) also supports that the incidence of malignancy is very low in this group patients.

Clinical presentation of TRC is very similar to benign masses and can not be differentiated in terms of size, localization and appearance. Therefore, in many cases, the diagnosis of malignancy can not be put until the operation (13). However, if remnant is hard, fixed, or irregular or associated with pathologic lymphadenopathy, carcinoma should be suspected (23). Additio- nally, increased risk of occult malignancy was reported in ETT especially when they include solid lesions (24). In our study, unlike from the other studies, features of ETT were identified with the US. The majority of ETT had benign sonografic features that was isoechoic, regular margin and type 1 vascularization and was localized in at the level of the hyoid bone. In our series, the absence of malignancy may result from benign sonographic features detected in our patients.

In many studies, the diagnosis of malignancy was performed incidentally with histopathological evaluation after surgery (13). Thus, the use of FNAB with ultrasound guidance may enhance the preoperative diagnosis. Carcinoma arising from the thyroglossal duct remnants constitutes a very uncommon histopathological entity (22). In our series, similarly, we did not observe any malignant cytology result. Because of the low prevalence of malignancy in ETT, we think FNAB is probably not cost-effective or appropriate.

In conclusion, we evaluated the clinic importance of ETT detected incidentally in the midline of neck as a single center experience. Especially in patients with a history of thyroidectomy, the thyroid masses in the midline of the neck can be found as incidental with imaging methods. Our results suggests that the incidence of malignancy in ETT group is much lower than orthotopic thyroid nodules, and they are mostly benign. Therefore, we believe that it would be appropriate to follow-up of that midline masses if there is no sonographic features indicating malignancy.

Acknowledgments: none.

Disclosure: no potential conflict of interest relevant to this article was reported.

\section{REFERENCES}

1. De Felice M, Di Lauro R. Thyroid development and its disorders: genetics and molecular mechanisms. Endocr Rev. 2004;25(5):722-46.

2. Batsakis JG, El-Naggar AK, Luna MA.Thyroid gland ectopias. Ann Otol Rhinol Laryngol. 1996;105(12):996-1000.

3. Tachibana T, OritaY, Fujisawa M, Ogawara Y. Papillary thyroid carcinoma arising from a median ectopic thyroid with no thyroglossal duct remnant. Acta Med Okayama. 2013;67(1):61-4.

4. Xu JJ, Kwan K, Fung K. Papillary thyroid carcinoma in a lateral neck cyst: primary of ectopic thyroid tissue versus cystic metastasis. J Laryngol Otol. 2013;127(7):724-7.

5. Choi YM, Kim TY, Song DE, Hong SJ, Jang EK, Jeon MJ, et al. Papillary thyroid carcinoma arising from a thyroglossal duct cyst: a single institution experience. Endocr J. 2013;60(5):665-70.

6. LeeYS, Kim KJ, Kim BW, Chang HS, Park CS. Recurrence of papillary thyroid carcinoma in a remnant pyramidal lobe. ANZ J Surg. 2011;81(4):304. 
7. Baloch ZW, LiVolsi VA, Asa SL, Rosai J, Merino MJ, Randolph G, et al. Diagnostic terminology and morphologic criteria for cytologic diagnosis of thyroid lesions: a synopsis of the National Cancer Institute Thyroid Fine-Needle Aspiration State of the Science Conference. Diagn Cytopathol. 2008;36(6):425-37.

8. Park JY, Kim DW, Park JS, Kang T, Kim YW. The prevalence and features of thyroid pyramidal lobes as assessed by computed tomography. Thyroid. 2012;22(2):173-7.

9. Feisal TK, Prepageran N, Shahrizal T, Zulkiflee AB. Unusual parapharyngeal lesion: aberrant thyroid gland. Singapore Med J. 2008;49(5):e137-8.

10. Subramony C, Baliga M, Lemos LB. Follicular carcinoma arising in ectopic thyroid tissue: case report with fine-needle aspiration findings. Diagn Cytopathol. 1997;16(1):39-41.

11. Sauk JJ. Ectopic lingual thyroid. J Pathol. 1970;102(4):239-43.

12. Izenstark JL, Forsaith $\mathrm{AL}$, Horwitz NH. The pyramidal lobe in thyroid imaging. J Nucl Med. 1969;10(8):519-24.

13. Fish J, Moore RM. Ectopic thyroid tissue and ectopic thyroid carcinoma: a review of the literature and report of a case. Ann Surg. 1963;157(2):212-22.

14. Di Benedetto V. Ectopic thyroid gland in the submandibular region simulating a thyroglossal duct cyst: a case report. J Pediatr Surg. 1997;32(12):1745-6.

15. Babazade F, Mortazavi H, Jalalian H, Shahvali E. Thyroid tissue as a submandibular mass: a case report. J Oral Sci. 2009;51(4): 655-7.
16. Kousta E, Konstantinidis K, Michalakis C, Vorias M, Sambalis G, Georgiou $\mathrm{M}$, et al. Ectopic thyroid tissue in the lower neck with a coexisting normally located multinodular goiter and brief literature review. Hormones (Athens). 2005;4(4):231-4.

17. Bersaneti JA, Silva RD, Ramos RR, Matsushita MM, Souto LR. Ectopic thyroid presenting as a submandibular mass. Head Neck Pathol. 2011;5(1):63-6.

18. Gopal RA, Acharya SV, Bandgar T, Menon PS, Marfatia H, Shah NS. Clinical profile of ectopic thyroid in Asian Indians: a singlecenter experience. Endocr Pract. 2009;15(4):322-5.

19. Yoon JS, Won KC, Cho IH, Lee JT, Lee HW. Clinical characteristics of ectopic thyroid in Korea. Thyroid. 2007;17(11):1117-21.

20. Ranade AV, Rai R, Pai MM, Nayak SR, Prakash, Krisnamurthy A, et al. Anatomical variations of the thyroid gland: possible surgical implications. Singapore Med J. 2008;49(10):831-4.

21. Shah BC, Ravichand CS, Juluri $S$, Agarwal A, Pramesh CS, Mistry RC. Ectopic thyroid cancer. Ann Thorac Cardiovasc Surg. 2007;13(2):122-4.

22. Heshmati HM, Fatourechi V, van Heerden JA, Hay ID, Goellner JR. Thyroglossal duct carcinoma: report of 12 cases. Mayo Clin Proc. 1997;72(4):315-9.

23. Mazaferri EL. Thyroid cancer in thyroglossal duct remnants: a diagnostic and therapeutic dilemma. Thyroid. 2004;14(5):335-6.

24. Park MH, Yoon JH, Jegal YJ, Lee JS. Papillary thyroglossal duct cyst carcinoma with synchronous occult papillary thyroid microcarcinoma. Yonsei Med J. 2010;51(4):609-11. 